Article

\title{
Compositional Dependence of Pore Structure, Strengthand Freezing-Thawing Resistance of Metakaolin-Based Geopolymers
}

\author{
Dongming Yan, Lingjun Xie, Xiaoqian Qian, Shaoqin Ruan and Qiang Zeng * (] \\ College of Civil Engineering and Architecture, Zhejiang University, Hangzhou 310058, China; \\ dmyan@zju.edu.cn (D.Y.); 21512179@zju.edu.cn (L.X.); qianxq1@zju.edu.cn (X.Q.); sruan001@zju.edu.cn (S.R.) \\ * Correspondence: cengq14@zju.edu.cn
}

Received: 14 June 2020; Accepted: 29 June 2020; Published: 3 July 2020

check for updates

\begin{abstract}
The understanding of the composition dependent properties and freezing-thawing (F-T) resistance of geopolymer materials is vital to their applications in cold regions. In this study, metakaolin-based geopolymer (MKG) mortars were fabricated by controlling the $\mathrm{Si} / \mathrm{Al}$ ratio and the $\mathrm{Na} / \mathrm{Al}$ ratio. The pore structure and strength were measured by mercury intrusion porosimetry and compression tests, respectively, which both showed obvious correlations with the material composition. Mass loss, strength loss, visual rate, and microscopic observation were adopted to assess the changes of the material properties and microstructure caused by F-T loads. The results showed that the strength-porosity relationship roughly followed a linear plot. Increases of the Si / Al ratio increased the capillary pore volume, but decreased the gel pore volume and the F-T resistance. Increases of the $\mathrm{Na} / \mathrm{Al}$ ratio decreased the gel pore, but roughly enhanced the F-T resistance. The MKG mortar at the $\mathrm{Na} / \mathrm{Al}$ ratio of 1.26 showed the lowest total pore volume and the best F-T resistance. The mechanisms of our experimental observations were that the abundantly distributed air voids connected by the capillary pores facilitated the relaxation of hydraulic pressures induced by the freezing of the pore liquid. The findings of this work help better clarify the compositional dependence of the pore structure, strength, and freezing-thawing resistance of MKG materials and provide fundamental bases for their engineering applications in cold regions.
\end{abstract}

Keywords: geopolymer; alkaline activator material; pore structure; freezing-thawing

\section{Introduction}

The great amount of $\mathrm{CO}_{2}$ emissions from the production of ordinary Portland cement (OPC), around $0.8 \mathrm{~kg} \mathrm{CO}_{2}$ per $\mathrm{kg}$ OPC [1], provides significant engineering, social-economic, and ecologic incentives to replace OPC with green cementitious materials with low $\mathrm{CO}_{2}$ emissions. Geopolymer, a type of inorganic alumino-silicate polymer synthesized from predominantly silicon ( $\mathrm{Si}$ ) and aluminum (Al) materials of geologically active minerals, may be a preferable binding material that can glue aggregates to fabricate concrete [2,3]. Most importantly, the $\mathrm{CO}_{2}$ emissions for producing one ton of geopolymer are only $20 \%$ of those for OPC [3]. The economical and environmental benefits would be further raised when geopolymers are synthesized with solid wastes with high value added applications [4-9]. The cementing or geopolymerization process of geopolymer precursors with alkaline activators can rapidly proceed to form a three-dimensional polymeric structure with complex Al-O-Si bonds and to generate continual material skeletons that enable high strengths [10]. With those advantages, geopolymer-based materials possess a series of excellent performances with promising potentials in engineering applications, including high mechanical strength, great fire resistance, enhanced leaching resistance, and improved contaminate stabilization [11-15]. 
The engineering performances of geopolymer materials are highly dependent on the material composition, synthesizing method, and curing scheme [10,11,16-19]. Among these factors, the material composition may play the most important role, because it decisively impacts the material structures, mechanical properties, and durability performances. For example, the $\mathrm{Si} / \mathrm{Al}$ ratio and the $\mathrm{Na}(\mathrm{K}) / \mathrm{Al}$ ratio are generally elaborately designed to promote the mechanical properties of geopolymer materials. Rowles and Connor [11] found that metakaolin-based geopolymers (MKG) at the Si/ Al ratios of 2-2.5 and $\mathrm{Na} / \mathrm{Al}$ ratios of 1-1.5 showed optimized strengths. Using extensive experimental tests and statistic analyses, Lahoti et al. [17] reported that the $\mathrm{Si} / \mathrm{Al}$ ratios between 1.5 and 2.2 and the $\mathrm{Na} / \mathrm{Al}$ ratios between 0.8 and 1.5 enabled the fabrication of high strength MKG mortars over $60 \mathrm{MPa}$. Composition designs not only impact the material strength, but also alter the pore structure of MKG materials. For example, Duxon et al. [20] tested the pore size distribution (PSD) of MKG materials at different $\mathrm{Si} / \mathrm{Al}$ ratios and found that the rise of the $\mathrm{Si} / \mathrm{Al}$ ratio would narrow the pore sizes at the nanoscale. Nevertheless, these pore structure alterations may lead to different responses of geopolymer materials to freezing-thawing (F-T) cycles, which has not been clarified in previous studies.

The durability of geopolymer materials against F-T loads faces great challenges when geopolymer-based structures are in cold regions especially for hydraulic engineering applications, such as dams, aqueducts, and docks. One important challenge is that the pore structure of geopolymer materials varies with the material composition [20]. Therefore, the ordinary tests on the mechanical performances of geopolymer materials subject to F-T loads are far from approaching the real F-T degradation in the materials [21-23].

As an important durability index, F-T resistance has been widely tested in ordinary structure materials such as concrete, mortar, and masonry [24-26]. For all types of porous materials, the F-T damage mechanisms are similar. Generally, F-T damages occur when the pore pressures built from the transition of pore water to ice exceed the material strength [27-31]. Generally, the freezing pore pressures consist of the hydraulic pressures caused by the water-ice density differences and the crystallization pressures induced by the free energy differences [32,33]. The pore confinement will greatly influence the freezing process of water [28,34,35], which, consequently, impacts the frost damages of porous materials. Therefore, it is difficult to explore the F-T resistances of porous materials with different pore structures.

In the present work, we aimed to deepen the understandings of correlations between the pore structure and F-T resistance of MKG materials. MKG mortars with different pore structures were synthesized by controlling the $\mathrm{Si} / \mathrm{Al}$ ratio and the $\mathrm{Na} / \mathrm{Al}$ ratio. The pore structure of the MKG mortars was measured by mercury intrusion porosimetry (MIP), and its correlations to the compressive strengths were evaluated. The F-T performances of the MKG mortars were assessed and linked to the pore structure. The results of this study shed much light on the compositional dependence of the pore structure, strength, and freezing-thawing resistance of MKG materials.

\section{Experiments}

\subsection{Materials and Specimen Preparation}

A commercial metakaolin powder (Metamax, Basf Co. LTD., Shanghai, China) was used as the alumino-silicate source of the geopolymer materials. Using laser particle size analysis (LS-230, Coulter), the mean particle size was measured as $5.91 \mu \mathrm{m}$, and the 90\%-passed particle size was $13.59 \mu \mathrm{m}$. The particle size distribution of the metakaolin powder is shown in Figure 1a. The packing density of the metakaolin powder was $0.422 \mathrm{~g} / \mathrm{mL}$. The chemical composition of the metakaolin powder was measured by X-ray fluorescence (XRF) spectrometer analysis (SHIMADU XRF-1800, Shimadzu Global Laboratory Consumables Co., Ltd. Shanghai, China). $\mathrm{SiO}_{2}$ and $\mathrm{Al}_{2} \mathrm{O}_{3}$ occupied $57.47 \mathrm{wt} . \%$ and 39.81 wt.\% of the total oxides, respectively (Table 1). The XRD patterns of the metakaolin are shown in Figure $1 \mathrm{~b}$. Only amorphous halo and anatase are observed in the figure, suggesting that the metakaolin contained the amorphous $\mathrm{SiO}_{2}$ and $\mathrm{Al}_{2} \mathrm{O}_{3}$ with highly reactive potentials. 
(a)

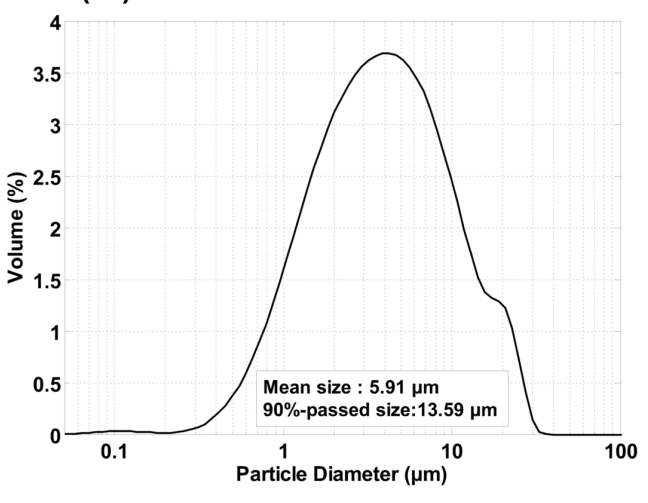

(b)

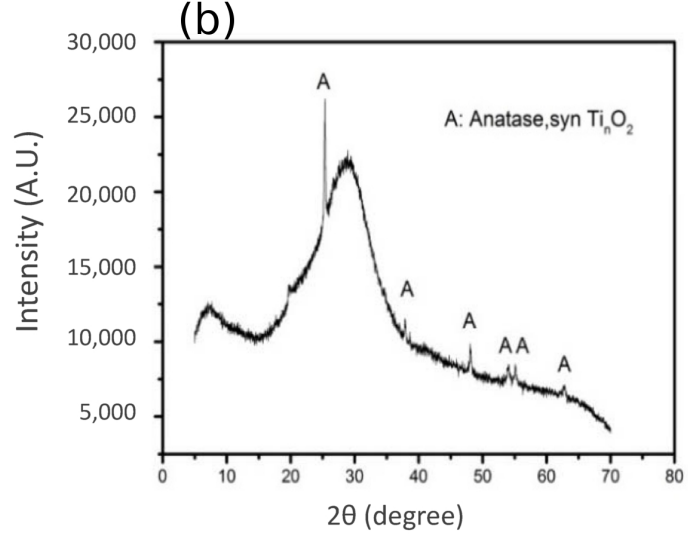

Figure 1. Particle size distribution (a) and XRD patterns (b) of the metakaolin powder.

Table 1. Chemical components of the metakaolin powder.

\begin{tabular}{llllllll}
\hline Composition & $\mathrm{SiO}_{2}$ & $\mathrm{Al}_{2} \mathbf{O}_{3}$ & $\mathrm{TiO}_{2}$ & $\mathrm{Fe}_{2} \mathbf{O}_{3}$ & $\mathbf{N a}_{2} \mathbf{O}$ & $\mathbf{K}_{2} \mathbf{O}$ & $\mathbf{C a O}$ \\
\hline Mass content (\%) & 57.47 & 39.81 & 1.79 & 0.43 & 0.27 & 0.21 & 0.04 \\
\hline
\end{tabular}

The alkaline activator used in this work was prepared by liquid sodium silicate $\left(\mathrm{SiO}_{2}=27.35 \%\right.$, $\mathrm{Na}_{2} \mathrm{O}=8.42 \%$, and $\left.\mathrm{H}_{2} \mathrm{O}=64.23 \%\right)$ and pellet sodium hydroxide $\left(\mathrm{Na}_{2} \mathrm{O}=77.4 \%, \mathrm{H}_{2} \mathrm{O}=22.5 \%\right.$, and impurity $=0.1 \%$ ). Fine sands with a fineness modulus of 1.75 and a density of $2510 \mathrm{~kg} / \mathrm{m}^{3}$ were adopted as the fine aggregates for preparing the MKG mortars.

In order to investigate the possible influences of material composition $(\mathrm{Si} / \mathrm{Al}$ ratio and $\mathrm{Na} / \mathrm{Al}$ ratio) on the pore structure and mechanical properties of MKG materials, two mortar groups were designed. For the first group (MKG-1 to MKG-3), the Si/ Al ratios varied from 2.01 to 2.62 with the $\mathrm{Na} / \mathrm{Al}$ ratio fixed at 1.01. For the second group (MKG-3 to MKG-5), the Si/Al ratio was fixed at 2.62 , while the $\mathrm{Na} / \mathrm{Al}$ ratio increased from 1.01 to 1.36. The mix proportions and nomenclature are shown in Table 2. In all mixes, a water-to-binder $(\mathrm{w} / \mathrm{b})$ ratio of 0.62 and a sand-to-binder $(\mathrm{s} / \mathrm{b})$ ratio of 3 were used, so that the influences of $\mathrm{w} / \mathrm{b}$ and $\mathrm{s} / \mathrm{b}$ could be eliminated. The alkaline activators were first synthesized according to the stoichiometric balances required by the different $\mathrm{Si} / \mathrm{Al}$ and $\mathrm{Na} / \mathrm{Al}$ ratios. After settling down for $12 \mathrm{~h}$, the activator solutions were readily prepared for the geopolymer synthesis.

Table 2. Mix proportions of the metakaolin-based geopolymer (MKG) concretes.

\begin{tabular}{lllllll}
\hline Mix ID & Metakaolin & Water Glass & NaOH & Water & Si/Al & Na/Al \\
\hline MKG-1 & 1016 & 640 & 193 & 410 & 2.01 & 1.01 \\
MKG-2 & 936 & 993 & 138 & 197 & 2.32 & 1.01 \\
MKG-3 & 868 & 1290 & 84 & 17 & 2.62 & 1.01 \\
MKG-4 & 842 & 1251 & 136 & 31 & 2.62 & 1.26 \\
MKG-5 & 832 & 1233 & 156 & 38 & 2.62 & 1.36 \\
\hline
\end{tabular}

When preparing the fresh MKG mortars, a readily settled alkali activator solution was first poured into a Hobart mixer bowl, followed by the precisely weighed metakaolin powder and water. A low-speed stirring for $3 \mathrm{~min}$ was conducted to obtain the MKG paste slurries. After that, sands were added into the paste slurries with another 3 min stirring to homogenize the MKG mortar. The mortar slurries were then cast into cuboid molds with dimensions of $40 \times 40 \times 160 \mathrm{~mm}^{3}$. High-frequency vibrations were conducted on the fully filled molds to further remove the air bubbles entrapped in the mortars. The specimens, together with the molds, were covered with plastic film to avoid any loss of water that may cause microstructure alterations. They later experienced a standard curing $\left(20 \pm 1{ }^{\circ} \mathrm{C}\right.$ 
and $90 \%$ relative humidity) for $2 \mathrm{~d}$ to increase the strengths. After demolding, all the mortar specimens were stored in a curing chamber to $28 \mathrm{~d}$.

\subsection{Testing Methods}

\subsubsection{Strength}

Compressive strengths were tested in a TYE-300D (Jianyi experiment instrument Co. LTD., WuXi, Jiangsu, China) automatic mechanical testing machine with a loading speed of $2.4 \mathrm{kN} / \mathrm{s}$. Six specimens of each mix were tested and averaged to guarantee the data reliability and productivity.

\subsubsection{Freezing-Thawing}

F-T durability is important when MKG materials are applied in hydraulic engineering structures in cold regions. F-T tests were performed using a CDR-5 rapid freeze-thaw machine according to the Test Code for Hydraulic Concrete [36]. Before the F-T tests, all the specimens were immersed in tap water for 4 days to enhance the water saturation degrees. The mass of those water-filled specimens was weighed by a highly accurate balance and termed as the initial mass $m_{0}$. Later, the specimens were loaded in water-filled vessels with the water surface $20 \mathrm{~mm}$ higher than the top surfaces of the specimens. Those vessels that contained the MKG specimens and water were then removed into the F-T testing machine. The temperature was controlled between -17 and $8{ }^{\circ} \mathrm{C}$. A freezing (thawing) course took $1.5-2.5 \mathrm{~h}(1-1.5 \mathrm{~h})$ to decrease (raise) the temperature. One complete F-T course cost $2.5-4 \mathrm{~h}$.

After 50 F-T cycles, the specimens were removed from the freezing chamber, and the excess surface water was cleaned by absorbent papers. The mass of the surface saturated specimens was measured and termed as $m_{F T}$. The relative mass loss $\Delta m$ was evaluated as:

$$
\Delta m=\frac{m_{0}-m_{F T}}{m_{0}}
$$

When the specimens were completely damaged after the F-T loads, neither the strength nor the mass was measured.

\subsubsection{Pore Structure}

The central part of each MKG mortar was crushed into small MKG particles (around $10 \mathrm{~mm}$ in diameter) for MIP tests. Owing to the reproductive data and broad pore ranges of MIP [37], only one MIP test for each mortar was conducted. MIP tests were carried out using an Autopore IV 9510 (Micromeritics Instrument Corp., Norcross, GA, USA). The applied intrusion pressures were set from $1.4 \mathrm{kPa}$ to $207 \mathrm{MPa}$ with the equilibrium time of $10 \mathrm{~s}$ for each pressure step. Mercury fronts invade pores or cavities when the exerted forces are high enough to overcome the barriers induced by the surface forces on the pore curvatures. By accurately recording the mercury intrusion (extrusion) volume (or mass) at each pressurization step, the pore structure of a porous material can be assessed. Generally, the Washburn equation [38] is used to link the applied pressures $(P)$ to the pore sizes $D$, i.e., $D=-4 \gamma \cos \theta / P$, where $\gamma$ is the surface tension of mercury and $\theta$ is the contact angle between mercury and the pore wall. Note that the Washburn equation requires the gradually sized and connected pore system in cylindrical geometry. By taking the commonly used physical parameters of mercury, i.e., the contact angle of $130^{\circ}$ and the surface tension of $485 \mathrm{~N} / \mathrm{m}$ [39], the minimum and maximum accessible pore sizes, according to the Washburn equation, were estimated as $6 \mathrm{~nm}$ and 360 $\mu \mathrm{m}$, corresponding to the maximum and minimum applied pressures, respectively.

\subsubsection{Micro Morphology}

Scanning electron microscopy (SEM) in back-scattered electron (BSE) mode was tested in an equipment of Quanta FEG 650 (Thermo Fisher Scientific, Beijing, China) to observe the microstructure 
alterations of the MKG mortars induced by F-T cycles. BSE images can more clearly distinguish the pore phase (including the cracks) from the solid skeletons, because they have different electron back-scattering coefficients. The MKG mortar particles before and after F-T loads were oven-dried at $40{ }^{\circ} \mathrm{C}$ for $24 \mathrm{~h}$ and impregnated with a quick-hardening epoxy resin. Later, the solidified resin-covered samples were ground and polished by various grades of sand papers and diamond suspensions. After a short carbon coating, the smooth and flat samples were loaded in a sample platform for the SEM/BSE tests. The voltage of $30 \mathrm{kV}$ and spot size of $5.0 \mathrm{~nm}$ were used to acquire the BSE images.

\section{Materials' Properties and Pore Structure}

\subsection{Pore Structure}

Table 3 summarizes some characteristic pore parameters of the MKG mortars from MIP tests, i.e., the total porosity $\phi_{T}$, average pore size $\left(D_{a}=4 V / A\right)$, specific surface area $(A)$, and threshold pore size $\left(D_{t}\right)$. Obviously, mortars with different mix proportions showed different characteristic pore parameters. Similar trends were found between the total porosity and specific surface area and between the average pore size and threshold pore size. They all coarsely reflected the pore structure features of a porous material. A higher total porosity (or specific surface area) generally implies a more porous structure, while a larger average pore size suggests a coarser pore structure. Threshold pore sizes measure the connected throats formed from the interparticle continuum [40], which is generally a featured index of permeability. More specific discussions about the pore data with the material compositions are given below.

Table 3. Characteristic pore parameters of the MKG mortars form mercury intrusion porosimetry (MIP) tests.

\begin{tabular}{lllll}
\hline Sample & Total Porosity $(\%)$ & Average Pore Size $(\mathbf{n m})$ & Specific Surface Area $\left(\mathbf{m}^{\mathbf{2}} / \mathbf{g}\right)$ & Threshold Pore Size $(\mathbf{n m})$ \\
\hline MKG-1 & 17.59 & 32.0 & 11.83 & 350.1 \\
MKG-2 & 15.81 & 27.1 & 12.43 & 350.1 \\
MKG-3 & 18.08 & 25.2 & 15.46 & 553.7 \\
MKG-4 & 13.01 & 84.5 & 3.25 & 675.9 \\
MKG-5 & 13.15 & 89.9 & 3.14 & 1049.4 \\
\hline
\end{tabular}

Figure 2 shows the MIP pore data of the MKG mortars, where the pore size distributions (PSDs) in the accumulative (APSD) and differential forms (DPSD) were acquired. While the MKG mortars showed different PSD shapes, similar physical interactions took place between the mercury fronts and pores. At the beginning of the MIP test, mercury first invaded the open cracks, gaps, cavities, and irregularities on the sample surfaces, which was termed as the surface-conformance effect [39]. This surface-conformance effect may be inevitable, because sample pretreatments such as cutting and drying [41] would always enhance the surface roughness. The rapid fillings of mercury at low pressures accounted for the rises in APSDs (Figure 2a) and the peaks in DPSDs at $100 \mu \mathrm{m}$ (Figure 2b). Analysis showed that the mercury volumes for covering the surface roughness were all around $0.01 \mathrm{~mL} / \mathrm{g}$ (Figure 2c), occupying 12-17\% of the total intrusion volumes (Figure 2d). The results may show that the MKG samples had similar surface roughness.

As the applied pressure increased, mercury fronts penetrated into the thinner pores. Rapid mercury rises were observed between 50 and 10,000 nm (Figure 2a), which can be cataloged as the capillary pores. They were the connected spaces among the metakaolin particles, hydration products, and fine aggregates (known as the inter-particle spaces). The invasion of mercury into those inter-particle spaces led to the intrusion peaks between 100 and $2000 \mathrm{~nm}$ (Figure $2 \mathrm{~b}$ and Table 3). It is noteworthy that MIP PSD always underestimates the pore sizes due to the "ink-bottle" effect [42]. Nevertheless, it measures the pore throats that establish the pore connections [40]. Pore analysis showed that the capillary pores between $50 \mathrm{~nm}$ and 10,000 nm occupied different volumes and ratios 
for different MKG mortars (Figure 2c,d). Specifically, more than 70 percent of the pores in the MKG-4 and MKG-5 samples were capillary pores (Figure 2d).

Under higher pressures, mercury could invade the pores below $50 \mathrm{~nm}$ (gel pores). Great PSD differences between the MKG mortars were found without uniform trends (Figure 2a,b). The MKG-1 sample had coarser PSDs and higher gel pore volumes than MKG-2 and MKG-3, while the MKG-5 and MKG-5 samples showed limited distributions and volumes of the gel pores (Figure 2c,d).

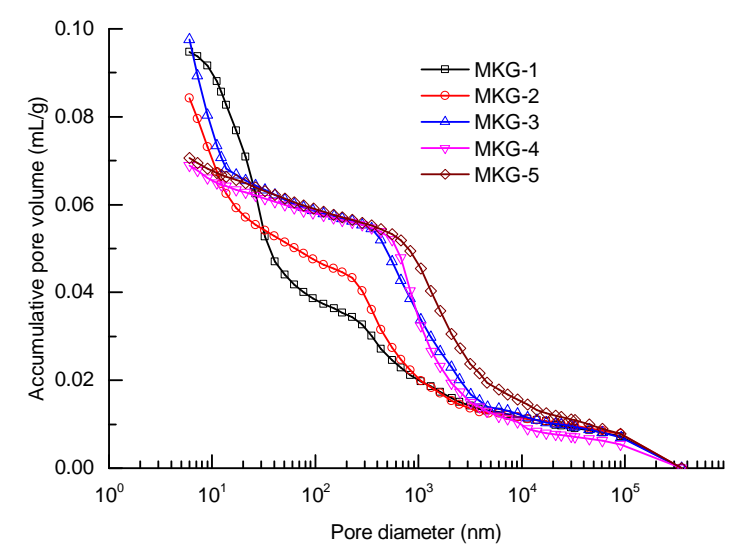

(a) APSD of the MKG samples before F-T loads

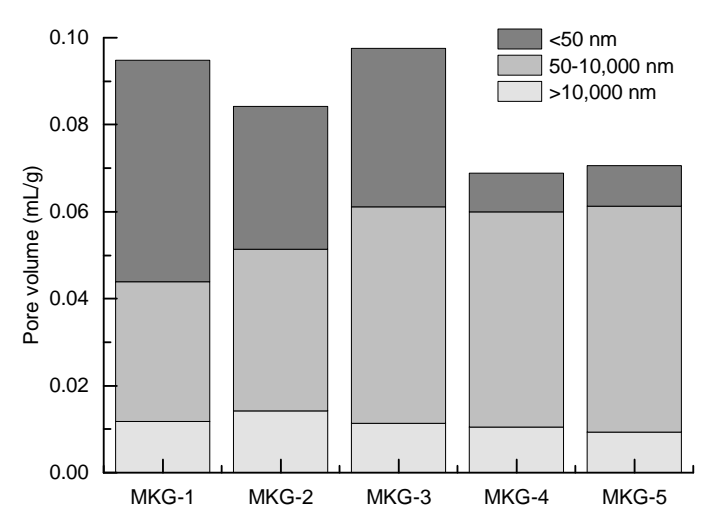

(c) Pore volumes in different sizes

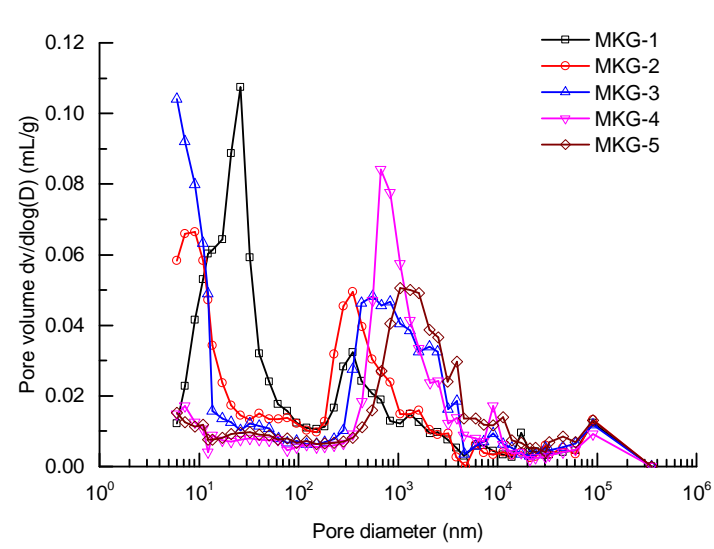

(b) DPSD of the MKG samples before F-T loads

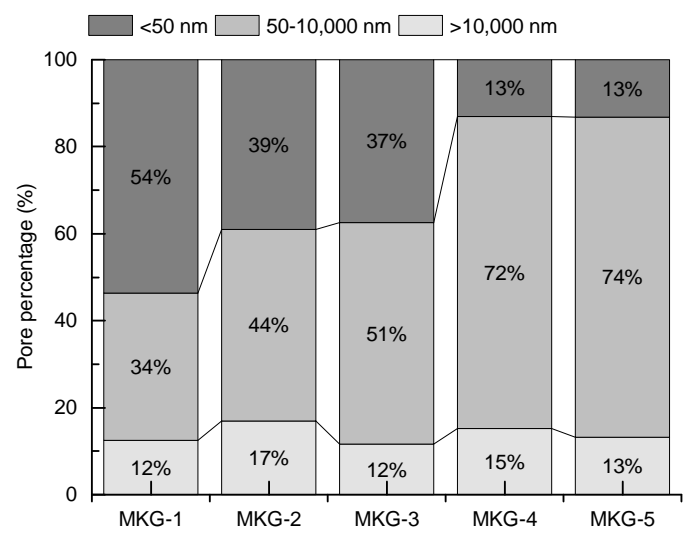

(d) Pore ratios in different sizes

Figure 2. Pore structure of the MKG mortars before freezing-thawing (F-T) loads: (a) accumulative pore size distribution (APSD) spectra; (b) differential PSD (DPSD) spectra; (c) pore volumes in different sizes; and (d) pore ratios in different sizes.

\subsection{Strength}

Figure 3 shows the statistical compressive strengths of the MKG mortars. Clearly, all the mortars showed relatively high strengths $(>57 \mathrm{MPa})$, suggesting that the mixes used in this work could fabricate geopolymer materials with good mechanical properties. Similar strength data were reported elsewhere [11,17].

Most granular-compacted materials (like concrete and geopolymer materials) accumulate strengths by increasing the compactness of solids or decreasing the volume of pores. Therefore, total porosity can be an indicator to predict material strength. Figure 4 shows the plots of compressive strength against total porosity. Roughly, the compressive strength decreased linearly with the total porosity, which can be expressed as:

$$
\sigma=\sigma_{0}(1-\alpha \phi)
$$


where $\sigma$ and $\sigma_{0}$ are the compressive strengths at current porosity $\phi$ and zero porosity, respectively; $\alpha$ is the coefficient. Equation (2) is also known as the Hasselmann equation for the strength-porosity relationship of porous materials [43].

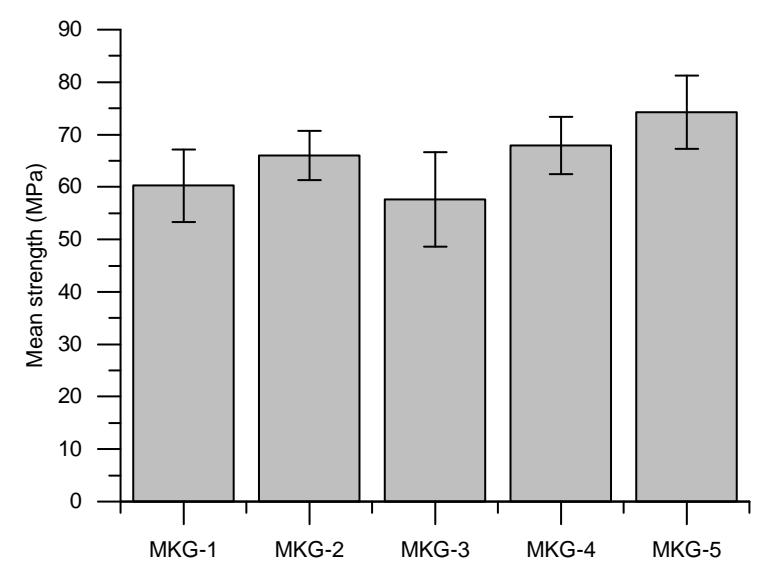

Figure 3. Statistical strengths of the MKG mortars.

Fitting of the compressive strength data with Equation (2) yielded $\sigma_{0}=99.74 \mathrm{MPa}, \alpha=0.022$. The obtained $\sigma_{0}$ was much larger than that of alkali-activated slag mortars [44], but close to that of geopolymer mortars prepared by slag, fly ash, and palm oil fuel ash [18]. The coefficient $\alpha$ was much lower than that reported in the literature $[18,44]$. The results implied the high strength of the solid matrix and the limited influence of total porosity.

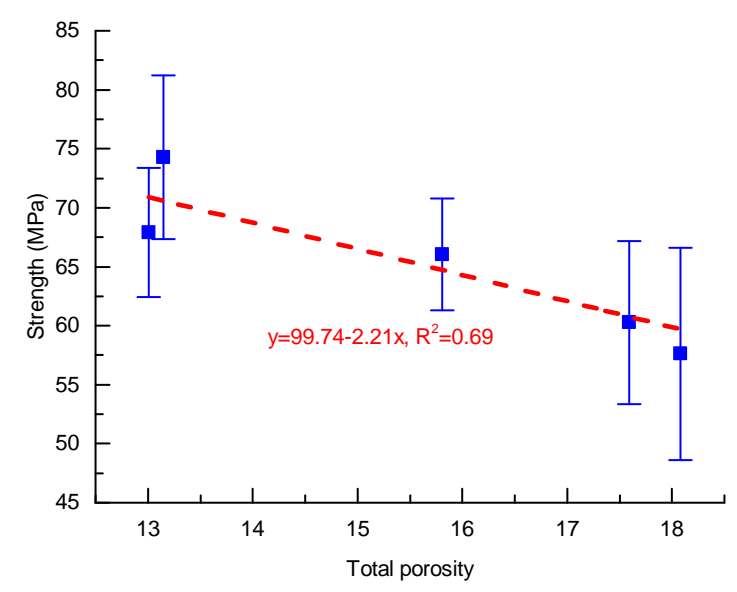

Figure 4. Relationships between strength and porosity.

\subsection{Roles of the Materials' Composition}

In order to better understand the effects of the $\mathrm{Si} / \mathrm{Al}$ ratio and the $\mathrm{Na} / \mathrm{Al}$ ratio on the strength and pore structure of the MKG mortars, specific analyses were performed on each factor. Figure 5 shows the compressive strengths and pore volumes in terms of the $\mathrm{Si} / \mathrm{Al}$ ratio and the $\mathrm{Na} / \mathrm{Al}$ ratio. The mix with the $\mathrm{Si} / \mathrm{Al}$ ratio at 2.32 showed the highest compressive strength $(\sigma=66.04 \mathrm{MPa})$, while the mixes with the other $\mathrm{Si} / \mathrm{Al}$ ratios showed slightly lower compressive strengths (Figure 5a). Meanwhile, increasing the $\mathrm{Si} / \mathrm{Al}$ ratio promoted the capillary pore volume, but decreased the gel pore volume (Figure 5c).

When the $\mathrm{Si} / \mathrm{Al}$ ratio was fixed at 2.62, the changes of the $\mathrm{Na} / \mathrm{Al}$ ratio caused monotonous changes of both compressive strengths and pore volumes. For example, as the $\mathrm{Na} / \mathrm{Al}$ ratio increased from 1.01 to 1.36 , the compressive strength increased from $57.63 \mathrm{MPa}$ to $74.28 \mathrm{MPa}$ with the promotion extents of 
$29 \%$, and the gel pore volume decreased from $0.0365 \mathrm{~mL} / \mathrm{g}$ to $0.0093 \mathrm{~mL} / \mathrm{g}$ with the decreasing extents of $75 \%$ (Figure $5 b, d$ ). The absolute capillary volume only showed minor changes as the $\mathrm{Na} / \mathrm{Al}$ ratio varied (Figure 5d), but the relative ratio of capillary pores increased significantly (Figure 2d).

The changes of strength and pore structure were the consequences of physico-chemical interactions among the metakaolin particles and alkaline activator. Because both the Si/Al ratio and the $\mathrm{Na} / \mathrm{Al}$ ratio were optimally selected according to the literature data [17] and our previous work [19], all the MKG mortars showed high compressive strengths. Our data did not follow the observation that materials with higher capillary pore volumes have lower strengths [45]. The reason is that the enhanced polymerization extents of geopolymer at the higher $\mathrm{Na} / \mathrm{Al}$ ratio (or $\mathrm{Na} / \mathrm{Si}$ ratio) could increase the compactness of the nanostructure, thus decreasing the nanopores and promoting the capillary pores [20].

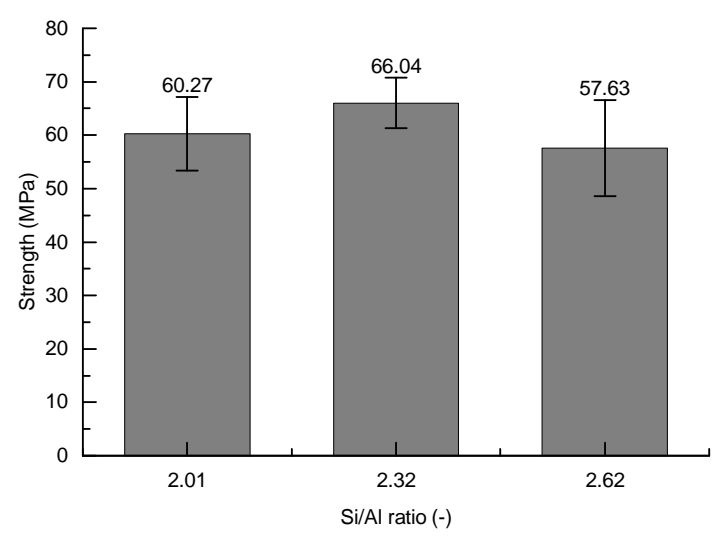

(a) Strength of the MKG mortars with different $\mathrm{Si} / \mathrm{Al}$ ratios

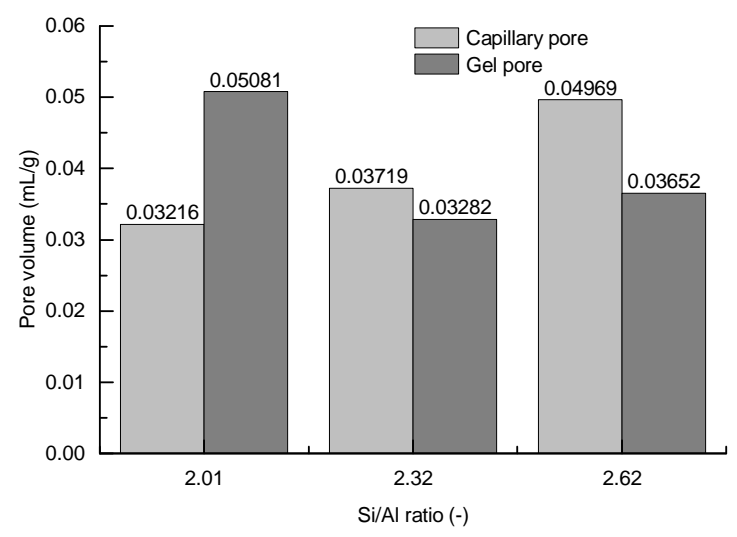

(c) Pores of the MKG mortars with different $\mathrm{Si} / \mathrm{Al}$ ratios

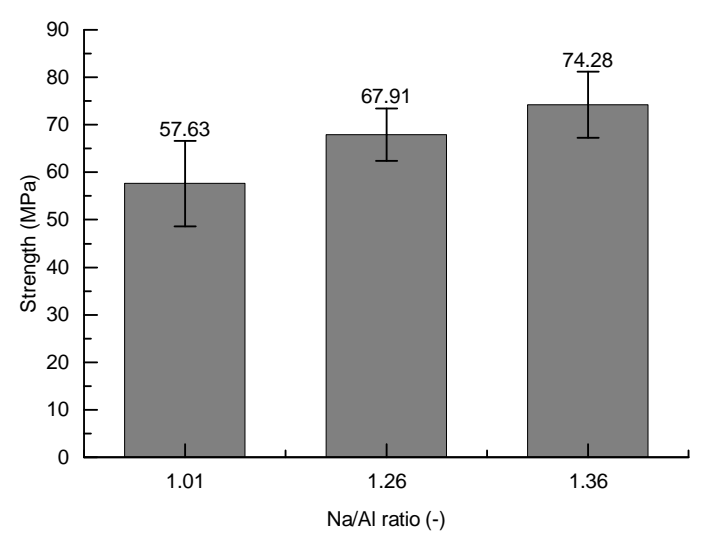

(b) Strength of the MKG mortars with different $\mathrm{Na} / \mathrm{Al}$ ratios

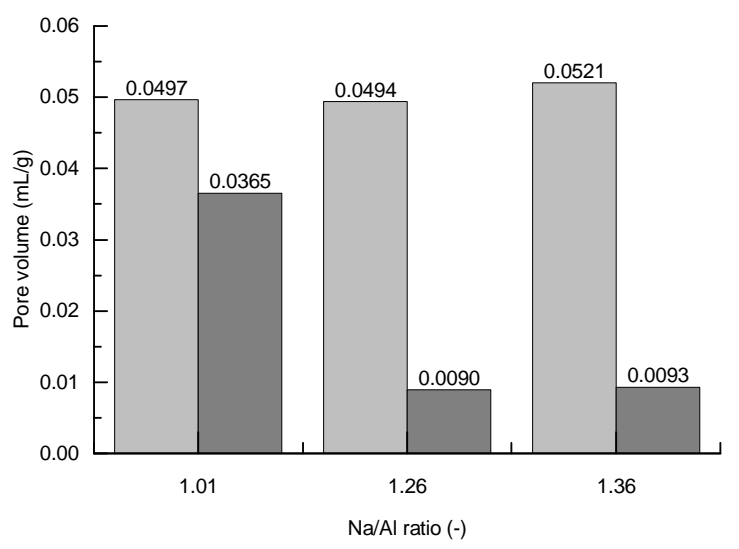

(d) Pores of the MKG mortars with different $\mathrm{Na} / \mathrm{Al}$ ratios

Figure 5. Compositional dependence of the strength and pore structure of the MKG mortars: strength of the MKG mortars versus (a) the Si/Al ratio; (b) Na/Al ratio, pores of the MKG mortars versus the (c) $\mathrm{Si} / \mathrm{Al}$ ratio and $(\mathrm{d}) \mathrm{Na} / \mathrm{Al}$ ratio.

\section{Freezing-Thawing Damages}

\subsection{Morphology, Mass Loss, and Strength Loss}

Figure 6 shows the photos of the MKG mortars after 50 F-T cycles. Serious surface spalling occurred on the MKG-1 specimens (Figure 6a), causing a mass loss of $21.04 \%$ (Figure 7a). The MKG-2 and MKG-3 specimens were completely damaged or pulverized into small mortar particles 
(Figure $6 \mathrm{~b}, \mathrm{c}$ ), thus referred to as $100 \%$ mass loss (Figure 7a). The MKG-4 and MKG-5 specimens showed minor or negligible visual changes (Figure 6d,e) and mass loss (Figure 7a).

(a)

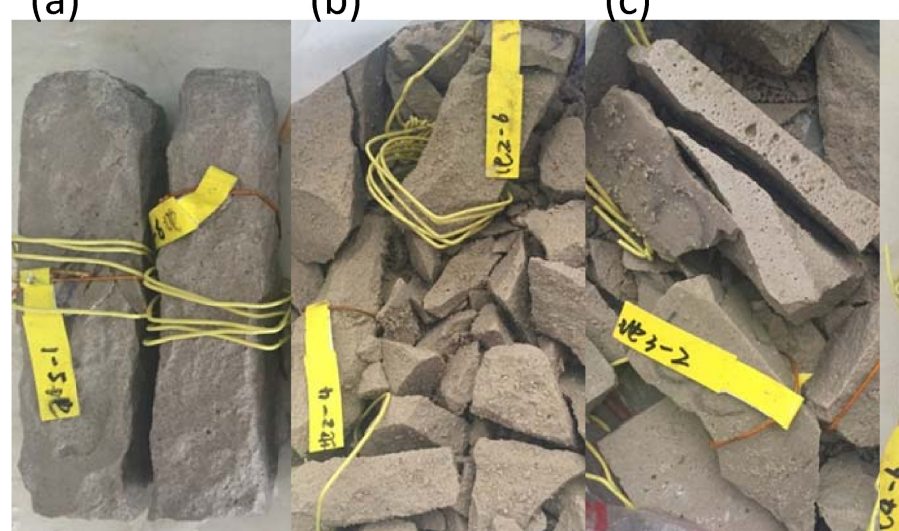

(d)

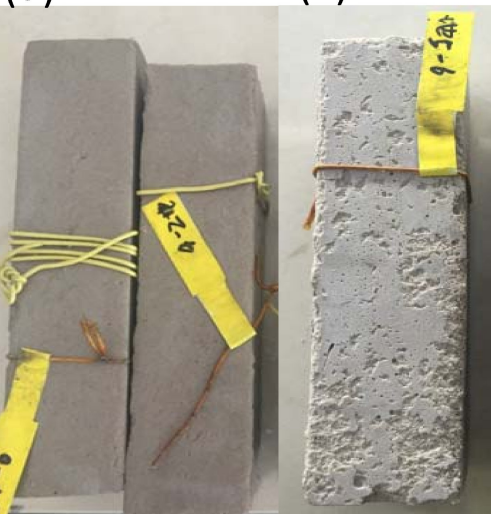

Figure 6. Pictures of the MKG mortars after 50 F-T cycles: (a) MKG-1; (b) MKG-2; (c) MKG-3; (d) MKG-4; and (e) MKG-5.

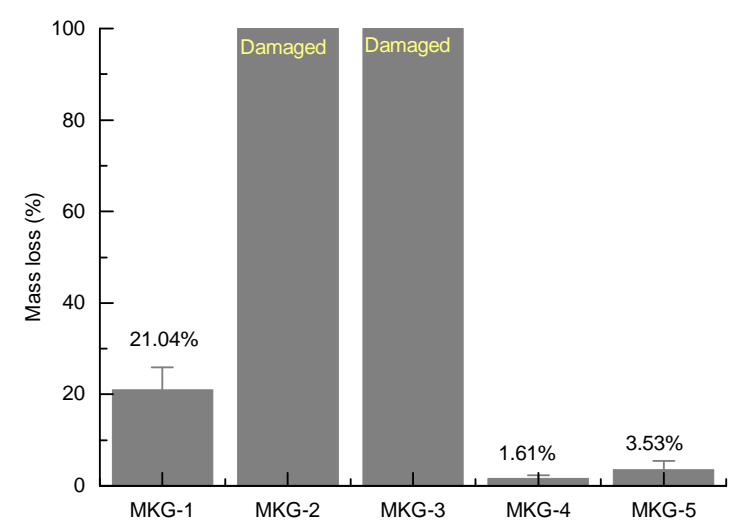

(a) Mass loss

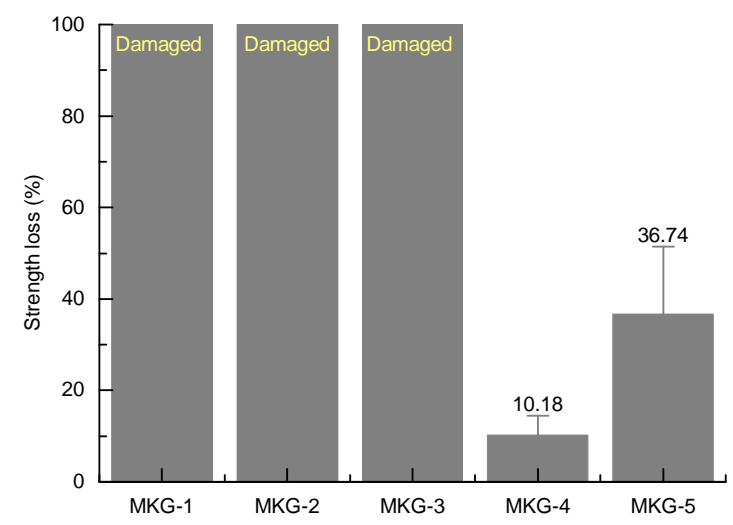

(b) Strength loss

Figure 7. Mass loss (a) and strength loss (b) of the MKG mortars after 50 F-T cycles.

Owing to the severe spalling and pulverization, the specimens of MKG-1, MKG-2, and MKG-3 were not suitable for strength tests. Those mortar mixes were therefore regarded to have $100 \%$ strength loss after F-T loads (Figure 7b). While the MKG-4 and MKG-5 mortars showed minor surface spalling, they had severe strength losses, i.e., $10.18 \%$ for MKG-4 and 36.74\% for MKG-5 (Figure 7b). This implied that serious F-T damages occurred in the materials. The results obtained from Figures 6 and 7 suggested that the order of F-T resistance of the MKG mortars could be rated as: MKG-4 > MKG-5 > MKG-1 > MKG-2 = MKG-3. This rate was roughly in accordance with the strength and porosity data provided in Section 3: materials with a higher strength (or lower porosity) also had better F-T resistance.

SEM/BSE tests were conducted on the MKG-4 and MKG-5 specimens with complete appearance to explore the F-T damages. Figure 8 selectively illustrates the BSE images of the MKG-4 and MKG-5 mortars. Clearly, several tortuous microcracks can be observed in the materials, which connected some air voids and/or big pores. Those cracks were different from the drying cracks that should be distributed in the geopolymer matrix with smeared cracking meshes [46]. The cracks would greatly decrease the compressive strength, but maintain the specimen mass before they were maturely developed to form the large cracks that caused the material spalling. While the MKG-5 specimen showed less cracks than the MKG-4 specimen, the cracks in the former material connected with each 
other, forming percolated cracks. This explained why the MKG-5 mortar showed severer mass and strength losses (Figure 7).

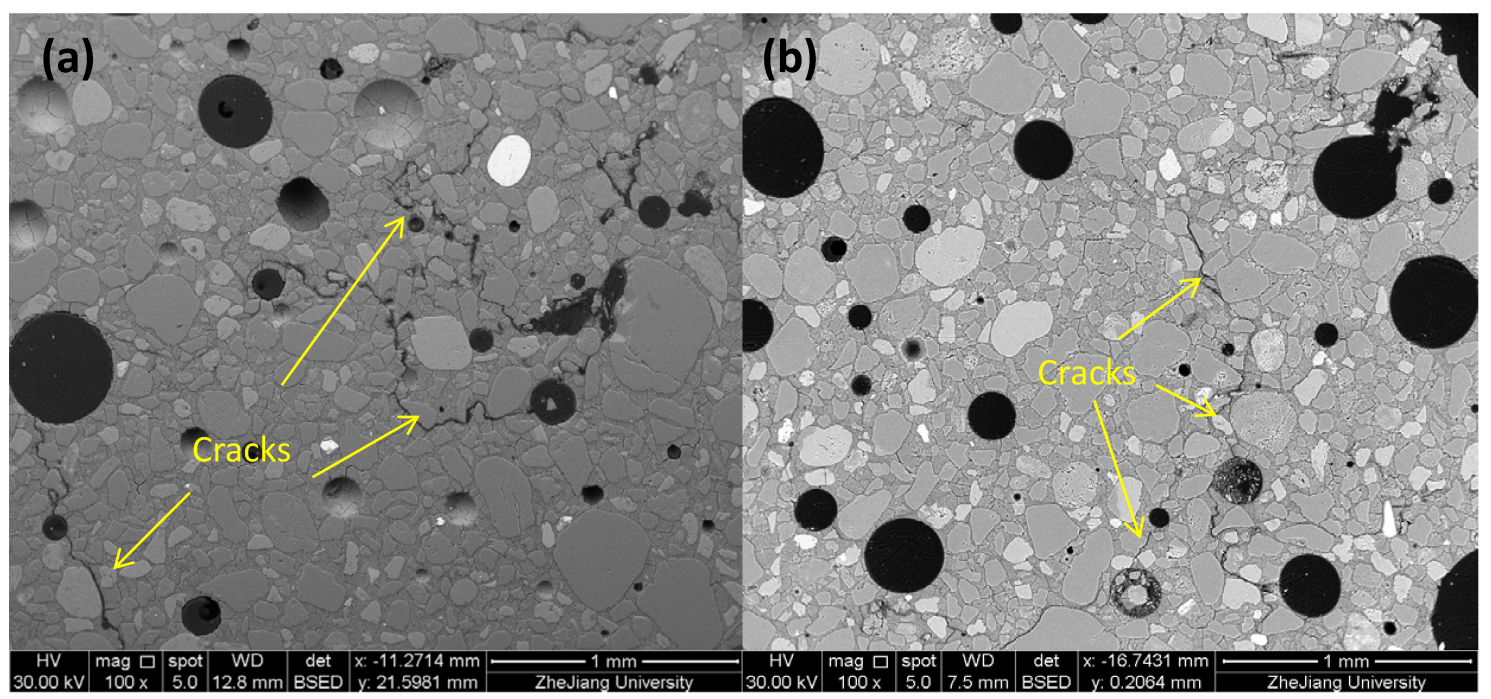

Figure 8. Typical SEM/BSE pictures of (a) MKG-4 and (b) MKG-5 specimens after F-T loads.

\subsection{Pore Structure Alterations}

The pore structure alterations of the MKG mortars after F-T loads were assessed by MIP tests. Figure 9 shows the PSD spectra and pore segmentation of the MKG mortars after F-T loads. At a first glance, both the APSD and DPSD spectra showed similar curves to those before F-T loads. This was reasonable, because F-T loads would not change the spatial compactness of the material system. For example, the first mercury rise in APSD and the peak in DPSD remained unchanged after F-T loads for most mixes, except that a slight rise in this part occurred for the MKG-5 mortar (Figure 9e). The F-T cracking enhanced the surface roughness, which, consequently, raised the surface-conformance effect (Figure 9f).

Careful examinations on two phases of the DPSD spectra were performed, which helped characterize the pore structure alterations caused by F-T loads. Phases A and B represent the gel pores below $50 \mathrm{~nm}$ and the capillary pores between 100 and 10,000 nm, respectively (Figure 9b). Comparative plots of the two phases between the mortars before and after F-T loads are drawn in Figure 9c,d. Surprisingly, the gel pores of all mortar mixes were raised (Figure 9c). For instance, the MKG-2 and MKG-3 mixes that appeared to have the severest F-T damages (Figure 6) showed the heaviest rises of the gel pores, and the gel pore ratios increased from $39 \%$ and $37 \%$ (Figure $2 \mathrm{~d}$ ) up to $44 \%$ and $43 \%$ (Figure 9f), respectively. Meanwhile, the capillary pores were narrowed (Figure 9d), and the pore volumes were decreased (Figure 9e). Those were contrary to the pore structure degradation reported elsewhere [23]. The anomalous gel and capillary pores' alterations did not directly reflect the material degradation caused by F-T loads, but might indicate the pore refinement induced by the continual polymerization of the materials immersed in water. A literature survey indicated that the first few F-T cycles may enhance the geopolymerization process, which helps refine the pore structure and even increase the strength [47-49]. The products of geopolymerization filled the coarse pores, which thus decreased the capillary pore fractions of MKG-4 and MKG-5 shown in Figure 9f. 


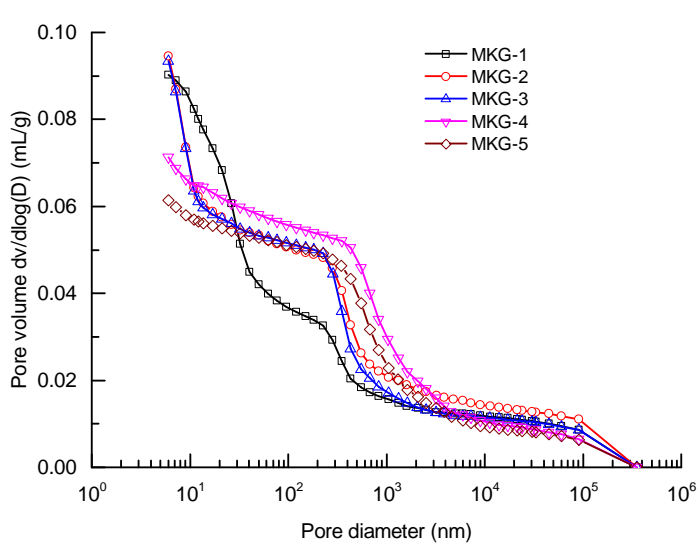

(a) APSD of the MKG samples after F-T loads

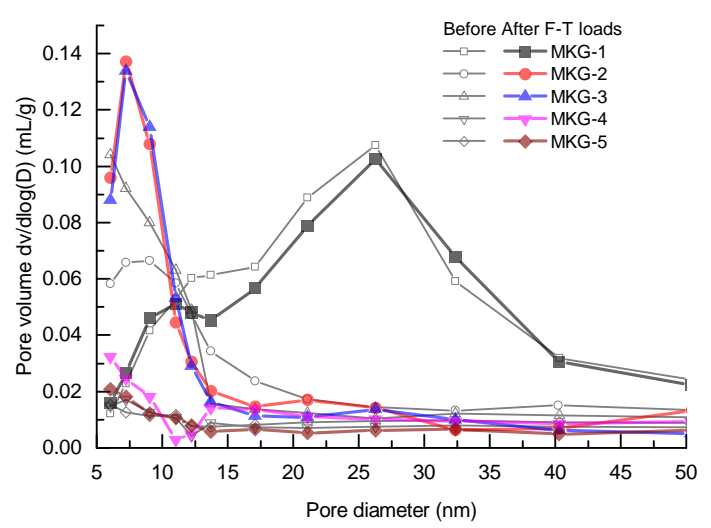

(c) DPSD of the MKG samples after F-T loads in Phase A

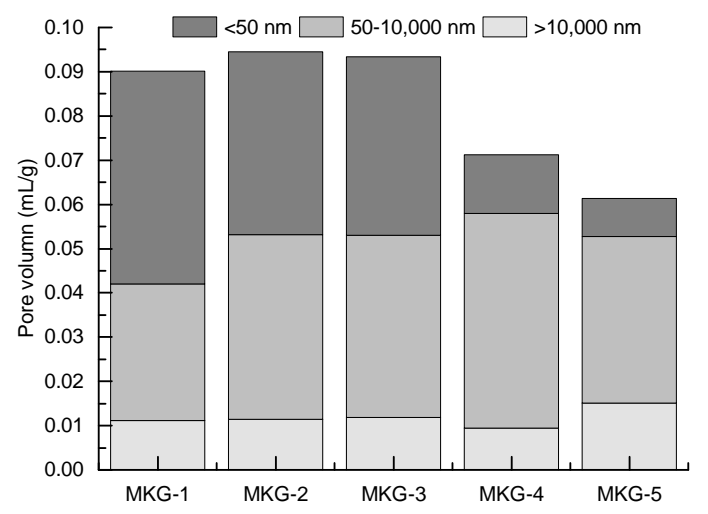

(e) Pore volumes in different sizes

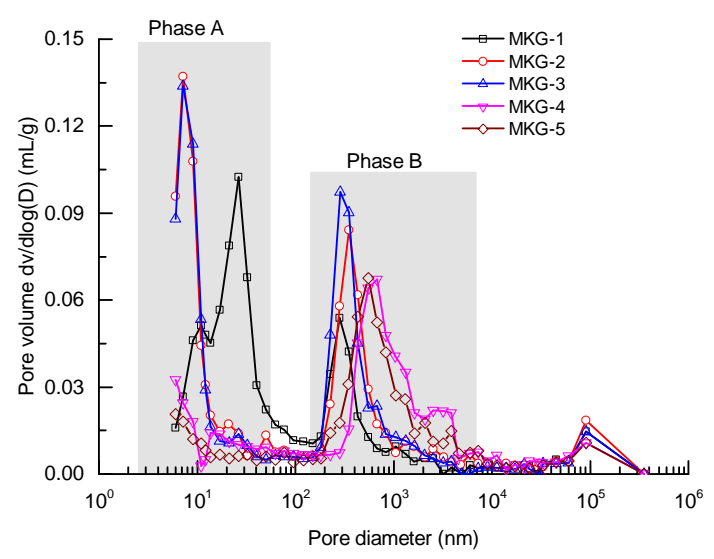

(b) DPSD of the MKG samples after F-T loads

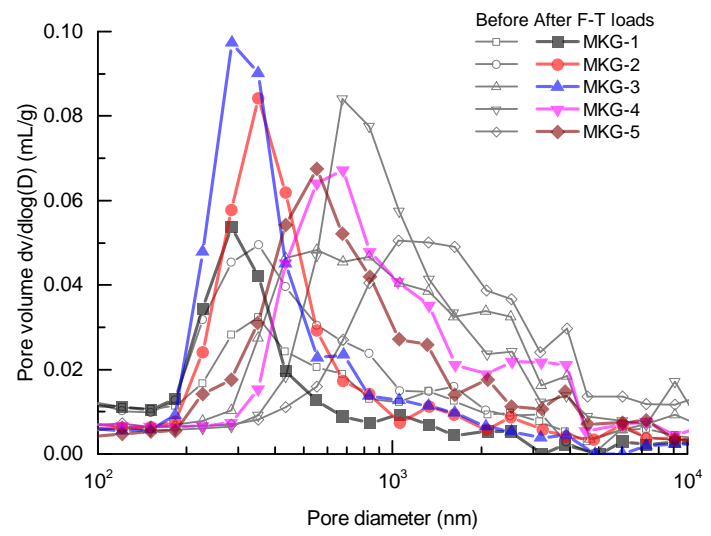

(d) DPSD of the MKG samples after F-T loads in Phase B

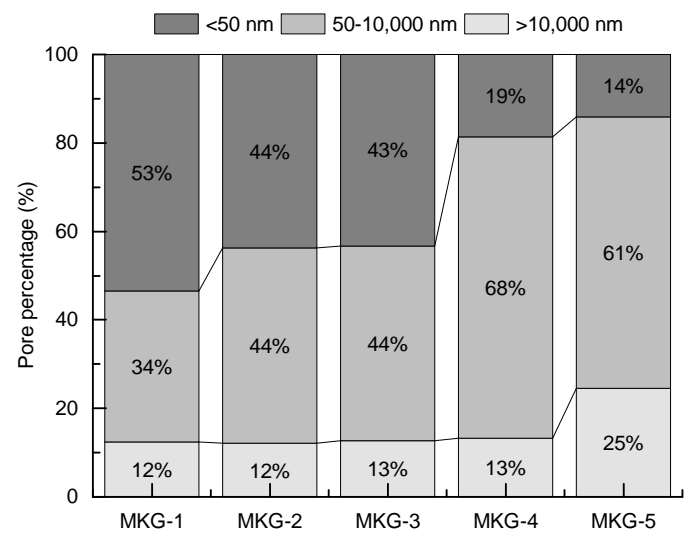

(f) Pore ratios in different sizes

Figure 9. Pore structure of the MKG mortars after F-T loads: (a) APSD spectra; (b) DPSD spectra; comparison of the pores in Phase A (c) and Phase B (d); (e) pore volumes in different sizes; and (f) pore ratios in different sizes.

\subsection{Further Discussion: Permeability Associated Pressure Relaxation}

In this work, experimental tests on the MKG mortars verified the compositional sensitivity of the strength and pore structure. Increasing the $\mathrm{Na} / \mathrm{Al}$ ratio tended to enhance the material strengths. A linear relationship was found between the compressive strength and total porosity (Figure 4). Except the volumes induced by the surface-conformance effect showing similar results, both the 
capillary pores and gel pores were highly dependent on the $\mathrm{Si} / \mathrm{Al}$ ratio and the $\mathrm{Na} / \mathrm{Al}$ ratio (Figure 5). While our experimental data testified that the geopolymer material with a higher strength also showed a better F-T resistance, we also observed the anomalies of the pore structure alterations after F-T loads (Figure 9). These data also raised a question: Why does an MKG material with a coarser pore structure show better F-T resistance? To address this question, we should understand the roles different pores played during freezing.

Figure 10 schematically illustrates the snapshots of a thin pore system and a coarse one during freezing. In the thin pore (or coarse pore) system, a big pore chamber was connected by thin channels (or coarse channels), and all the pores were filled with water before freezing. The thin pore system may capture the pore structures of MKG-1, MKG-2, and MKG-3, and the coarse one may represent those of MKG-4 and MKG-5; see Figure 2.
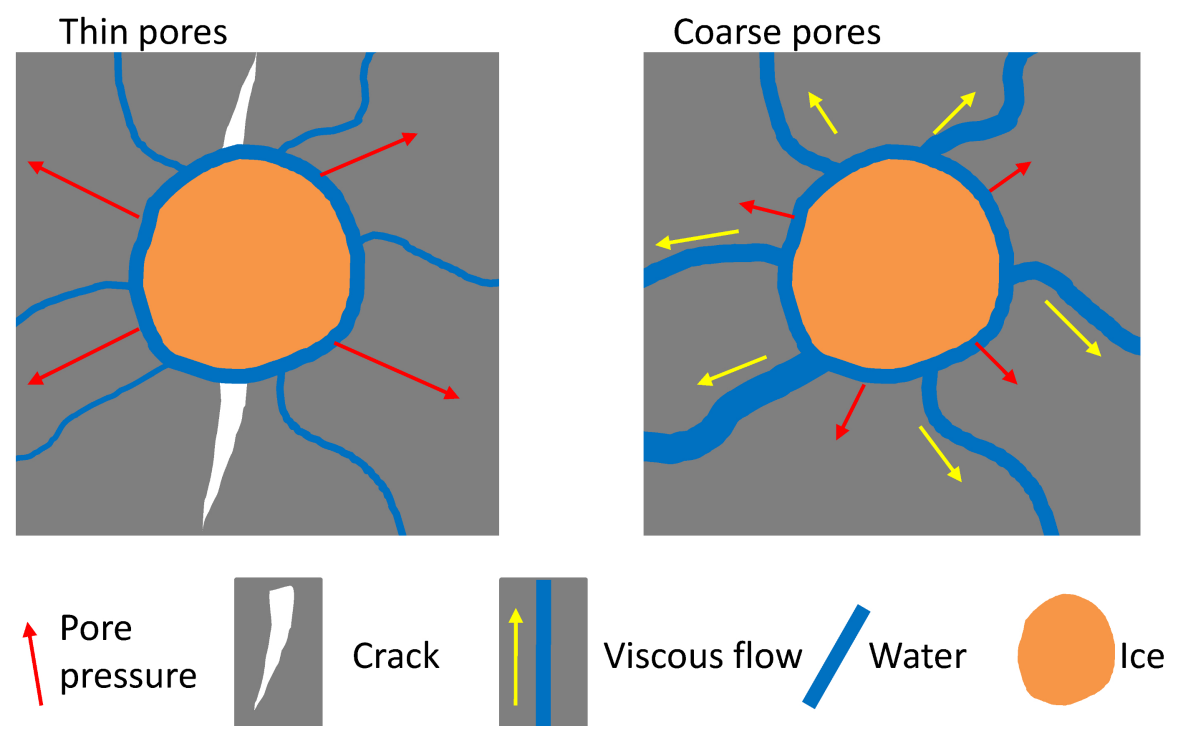

Figure 10. Schematic illustration of the freezing resistance differences between a material with thin pores and that with coarse pores.

When temperature decreased to a subzero value, the water confined in the big pore chamber began to freeze while the pore channels remained unfrozen. Freezing pressures (including the hydraulic pressure and crystallization pressure [33]) caused by the phase transition of water to ice in the confinement built up. The crystallization pressure would be locally exerted on the pore walls due to the free-energy differences between water and ice [32]. The hydraulic pressure that was exerted homogeneously on the pore walls through the unfrozen pore water, however, could be relaxed through the viscous flow of the pore water (Figure 10). This important feature was used by concrete scientists who homogeneously entrained air voids in the material matrix to shorten the water flow distance and thus mitigate the hydraulic pressures [50].

Generally, the hydraulic pressure relaxation is inversely proportional to the permeability of pore channels for water flow, which can be expressed as [51]:

$$
\Delta P_{h} \propto L t / K_{h}
$$

where $\Delta P_{h}$ is the changes of hydraulic pressure by relaxation, $L$ is the pore length, $t$ is the relaxation time, and $K_{h}$ is the permeability. According to Katz and Thompson [40], the permeability of a porous material can be predicted by the threshold pore size, $K_{h} \propto D_{T}^{-2}$. Equation (3) can be rewritten as:

$$
\Delta P_{h} \propto D_{T}^{2} L t
$$


or the pore pressure relaxation time $t$ can be expressed as:

$$
t \propto \Delta P_{h} / L D_{T}^{2}
$$

From Equations (4) and (5), it is easy to understand that less pore pressure relaxation can occur in the thin-pore system with the same relaxation time, or more time is required to relax the same pore pressures. Let us take the pore structure data of MKG-2 and MKG-5 as examples, and assume that the ice formation in the big pores accumulated the hydraulic pressures up to $10 \mathrm{MPa}$, while the pore length $L$ was the same. The MKG-2 mortar required $(1049.4 / 350.1)^{2} \approx 9$ times longer than MKG-5 to relax the hydraulic pressure at $10 \mathrm{MPa}$ according to Equation (5). This may explain why the MKG materials with the coarser pore structures showed better F-T resistances.

As the last comment, we should understand that the experimental data provided in this work did not imply that a material with a coarser pore structure would have better durability. Indeed, to promote the F-T resistance, the homogeneous entertainment of air voids in the material matrix may be the most effective routine. As shown in Figure 8, the MKG mortars with high F-T resistances (i.e., MKG-4 and MKG-5) contained air voids to accommodate the expelled water and mitigate the hydraulic pressures built by ice formation in the pores. Furthermore, the coarser pores would greatly decrease the material permeability, which in turn would decrease the resistance against the transport of harmful ions in the materials. Further rigorous pore structure design is required to optimize the properties of MKG materials before engineering applications.

\section{Conclusions}

- The MKG mortars with different $\mathrm{Si} / \mathrm{Al}$ ratios and $\mathrm{Na} / \mathrm{Al}$ ratios showed different MIP pore structures. Except the first mercury rises, which were identical to the surface fillings of the mercury under low pressures showing negligible volume changes, both the capillary pores and gel pores were greatly impacted by the $\mathrm{Si} / \mathrm{Al}$ ratio and the $\mathrm{Na} / \mathrm{Al}$ ratio. Increasing both the $\mathrm{Si} / \mathrm{Al}$ ratio and the $\mathrm{Na} / \mathrm{Al}$ ratio decreased the gel pores, but promoted the capillary pores.

- All the MKG mortars showed relatively high strengths. The strength decreased with increasing the total porosity, which roughly followed a linear plot.

- The MKG mortars showed different F-T resistances: MKG-4 > MKG-5 > MKG-1 > MKG-2 = MKG-3. The MKG mortars (MKG-1, MKG-2, and MKG-3) at Na/Al ratios lower than 1.26 all showed serious F-T damages. Increasing the $\mathrm{Na} / \mathrm{Al}$ ratio promoted the F-T resistance. F-T loads also caused obvious cracking of MKG-4 and MKG-5.

- MIP tests showed that the pore structures were refined after F-T loads, which was probably caused by the continual curing of the materials. Materials with finer pore structures showed worse F-T resistances owing to the slower pore pressure relaxation rates.

Author Contributions: All authors contributed equally to this work. All authors read and agreed to the published version of the manuscript.

Funding: This research was funded by National Key R\&D Program of China (grant number: 2018YFB0605700), National Natural Science Foundation of China (grant number: 51878602), and international cooperative research project from National Natural Science Foundation of China (grant number: 51950410579).

Acknowledgments: The authors acknowledged Yu Peng, Hamed Fazil and Shikun Chen for thoughtful discussions and technique helps.

Conflicts of Interest: The authors declare no conflict of interest.

\section{References}

1. Monteiro, P.J.; Miller, S.A.; Horvath, A. Towards sustainable concrete. Nat. Mater. 2017, 16, 698. [CrossRef]

2. Duxson, P.; Fernandez-Jimenez, A.; Provis, J.L.; Lukey, G.C.; Palomo, A.; van Deventer, J.S.J. Geopolymer technology: The current state of the art. J. Mater. Sci. 2007, 42, 2917-2933. [CrossRef] 
3. Duxson, P.; Provis, J.L.; Lukey, G.C.; van Deventer, J.S.J. The role of inorganic polymer technology in the development of 'green concrete'. Cem. Concr. Res. 2007, 37, 1590-1597. [CrossRef]

4. Kastiukas, G.; Ruan, S.; Liang, S.; Zhou, X. Development of precast geopolymer concrete via oven and microwave radiation curing with an environmental assessment. J. Clean. Prod. 2020, 255, 120290. [CrossRef]

5. Panda, B.; Ruan, S.; Unluer, C.; Tan, M. nvestigation of the properties of alkali-activated slag mixes involving the use of nanoclay and nucleation seeds for 3D printing. Compos. Part B-Eng. 2020, 186, 107826. [CrossRef]

6. Panda, B.; Ruan, S.; Unluer, C.; Tan, M. Improving the 3D printability of high volume fly ash mixtures via the use of nano attapulgite clay. Compos. Part B-Eng. 2019, 165, 75-83. [CrossRef]

7. Assi, L.N.; Carter, K.; Deaver, E.; Ziehl, P. Review of availability of source materials for geopolymer/ sustainable concrete. J. Clean. Prod. 2020, 263, 121477. [CrossRef]

8. El-Gamal, S.M.A.; Selim, F.A. Utilization of some industrial wastes for eco-friendly cement production. Sustain. Mater. Technol. 2017, 12, 9-17. [CrossRef]

9. Bassani, M.; Tefa, L.; Coppola, B.; Palmero, P. Alkali-activation of aggregate fines from construction and demolition waste: Valorisation in view of road pavement subbase applications. J. Clean. Prod. 2019, 234, 71-84. [CrossRef]

10. Provis, J.L. Geopolymers and other alkali activated materials: Why, how, and what? Mater. Struct. 2014, 47, 11-25. [CrossRef]

11. Rowles, M.; Connor, B.O. Chemical optimization of compressive strength of aluminosilicate geopolymer synthesized by sodium activation of metakaolinite. J. Mater. Chem. 2003 13, 1161-1165. [CrossRef]

12. Kohout, J.; Koutnik, P. Effect of Filler Type on the Thermo-Mechanical Properties of Metakaolinite-Based Geopolymer Composites. Materials 2020, 13, 2395. [CrossRef] [PubMed]

13. Peng, X.; Shuai, Q.; Li, H.; Ding, Q.; Gu, Y.; Cheng, C.; Xu, Z. Fabrication and fireproofing performance of the coal fly ash-metakaolin-based geopolymer foams. Materials 2020, 13, 1750. [CrossRef] [PubMed]

14. Cui, Y.; Gao, K.; Zhang, P. Experimental and statistical study on mechanical characteristics of geopolymer concrete. Materials 2020, 13, 1651. [CrossRef] [PubMed]

15. Roviello, G.; Chianese, E.; Ferone, C.; Ricciotti, L.; Roviello, V.; Cioffi, R.; Tarallo, O. Hybrid geopolymeric foams for the removal of metallic ions from aqueous waste solutions. Materials 2019, 12, 4091. [CrossRef]

16. White, C.E.; Page, K.; Henson, N.J.; Provis, J.L. In situ synchrotron X-ray pair distribution function analysis of the early stages of gel formation in metakaolin-based geopolymers. Appl. Clay Sci. 2013, 73, 17-25. [CrossRef]

17. Lahoti, M.; Narang, P.; Tan, K.H.; Yang, E. Mix design factors and strength prediction of metakaolin- based geopolymer. Ceram. Int. 2017, 43, 11433-11441. [CrossRef]

18. Kubba, Z.; Huseien, G.F.; Sam, A.R.M.; Shah, K.W.; Asaad, M.A.; Ismail, M.; Tahir, M.M.; Mirza, J. Impact of curing temperatures and alkaline activators on compressive strength and porosity of ternary blended geopolymer mortars. Case Stud. Constr. Mater. 2018, 9, e00205. [CrossRef]

19. Yan, D.; Chen, S.; Zeng, Q.; Xu, S.; Li, H. Correlating the elastic properties of metakaolin-based geopolymer with its composition. Mater. Des. 2016, 95, 306-318. [CrossRef]

20. Duxson, P.; Provis, J.L.; Lukey, G.C.; Mallicoat, S.W.; Kriven, W.M. Understanding the relationship between geopolymer composition, microstructure and mechanical properties. Colloids Surf. A 2005, 269, 47-58. [CrossRef]

21. Sun, P.J.; Wu, H.C. Chemical and freeze-thaw resistance of fly ash-based inorganic mortars. Fuel 2013, 111, 740-745. [CrossRef]

22. Topcu. I.B.; Toprak, M.U.; Uygunoglu, T. Durability and microstructure characteristics of alkali activated coal bottom ash geopolymer cement. J. Clean. Prod. 2014, 111, 211-217.

23. Zhao, R.; Yuan, Y.; Cheng, Z.; Wen, T.; Li, J.; Li, F.; Ma, Z.J. Freeze-thaw resistance of Class F fly ash-based geopolymer concrete. Constr. Build. Mater. 2019, 222, 474-483. [CrossRef]

24. Bocca, P.; Grazzini, A. Mechanical properties and freeze-thaw durability of strengthening mortars. J. Mater. Civ. Eng. 2013, 25, 274-280. [CrossRef]

25. Carpinteri, A.; Grazzini, A.; Lacidogna, G.; Manuello, A. Durability evaluation of reinforced masonry by fatigue tests and acoustic emission technique. Struct. Control Health Monit. 2014, 21, 950-961. [CrossRef]

26. Saez del Bosque, I.F.; Van den Heede, P.; De Belie, N.; Sanchez de Rojas, M.I.; Medina, C. Freeze-thaw resistance of concrete containing mixed aggregate and construction and demolition waste-additioned cement in water and de-icing salts. Constr. Build. Mater. 2020, 259, 119772. [CrossRef] 
27. Huang, S.; Ye, Y.; Cui, X.; Cheng, A.; Liu, G. Theoretical and experimental study of the frost heaving characteristics of the saturated sandstone under low temperature. Cold Reg. Sci. Technol. 2020, 74, 103036. [CrossRef]

28. Zeng, Q.; Fen-Chong, T.; Li, K. Freezing behavior of cement pastes saturated with NaCl solution. Constr. Build. Mater. 2014, 59, 99-110. [CrossRef]

29. Zeng, Q.; Fen-Chong, T.; Dangla, P.; Li, K. A study of freezing behavior of cementitious materials by poromechanical approach. Int. J. Solids Struct. 2011, 48, 3267-3273. [CrossRef]

30. Zeng, Q.; Li, K.; Fen-Chong, T. Elastic behavior of saturated porous materials under undrained freezing. Acta Mech. Sin. 2013, 29, 827-835. [CrossRef]

31. Zeng, Q.; Li, K.; Fen-Chong, T. Heterogeneous nucleation of ice from supercooled NaCl solution confined in porous cement paste. J. Cryst. Growth 2015, 409, 1-9. [CrossRef]

32. Scherer, G.W. Crystallization in pores. Cem. Concr. Res. 1999, 29, 1347-1358. [CrossRef]

33. Zeng, Q.; Li, K. Quasi-Liquid Layer on Ice and Its Effect on the Confined Freezing of Porous Materials. Crystals 2019, 9, 250. [CrossRef]

34. Engemann, S.; Reichert, H.; Dosch, H.; Bilgram, J.; Honkimaki, V.; Snigirev, A. Interfacial melting of ice in contact with $\mathrm{SiO}_{2}$. Phys. Rev. Lett. 2004, 92, 205701. [CrossRef] [PubMed]

35. Jahnert, S.; Vaca Chavez, F.; Schaumann, G.E.; Schreiber, A.; Schonhoff, M.; Findenegg, G.H. Melting and freezing of water in cylindrical silica nanopores. Phys. Chem. Chem. Phys. 2008, 10, 6039-6051. [CrossRef] [PubMed]

36. Test Code for Hydraulic Concrete; DL/T 5150-2017; The Electric Power Ministry of the People's Republic of China: Beijing, China, 2017.

37. Leóny León, C.A. New perspectives in mercury porosimetry. Adv. Colloid Interface Sci. 1998, 76-77, 341-72. [CrossRef]

38. Washburn, E.W. Note on a method of determining the distribution of pore sizes in a porous material. Proc. Natl. Acad. Sci. USA 1921, 7, 115-116. [CrossRef] [PubMed]

39. Zeng, Q.; Wang, X.; Yang, P.; Wang, J.; Zhou, C. Tracing mercury entrapment in porous cement paste after mercury intrusion test by X-ray computed tomography and implications for pore structure characterization. Mater. Charact. 2019, 151, 203-215. [CrossRef]

40. Katz, A.J.; Thompson, A.H. Quantitative prediction of permeability in porous rock. Phys. Rev. B 1986, 34, 8179. [CrossRef]

41. Zhang, Z.; Scherer, G.W., Evaluation of drying methods by nitrogen adsorption. Cem. Concr. Res. 2019, 120, $13-26$. [CrossRef]

42. Diamond, S. Mercury porosimetry: An inappropriate method for the measurement of pore size distributions in cement-based materials. Cem. Concr. Res. 2000, 30, 1517-1525. [CrossRef]

43. Hasselman, D.P.H.; Fulrath, R.M. Effect of small fraction of spherical porosity on elastic moduli of glass. J. Am. Ceram Soc. 1963, 47, 52-53. [CrossRef]

44. Shi, C. Strength, pore structure and permeability of alkali-activated slag mortars. Cem. Concr. Res. 1996, 26, 1789-1799. [CrossRef]

45. Akono, A.T.; Koric, S.; Kriven, W.M. Influence of pore structure on the strength behavior of particleand fiber-reinforced metakaolin-based geopolymer composites. Cem. Concr. Compos. 2019, 104, 103361. [CrossRef]

46. Balczar, I.; Korim, T.; Dobradi, A. Correlation of strength to apparent porosity of geopolymers-Understanding through variations of setting time. Constr. Build. Mater. 2015, 93, 983-988. [CrossRef]

47. Aygormeza, Y.; Canpolat, O.; Al-mashhadani, M.M. Assessment of geopolymer composites durability at one year age. J. Build. Eng. 2020, 32, 101453. [CrossRef]

48. Aygormeza, Y.; Canpolat, O.; Al-mashhadani, M.M.; Uysal M. Elevated temperature, freezing-thawing and wetting-drying effects on polypropylene fiber reinforced metakaolin based geopolymer composites. Constr. Build. Mater. 2020, 235, 117502. [CrossRef]

49. Zhao, M.; Zhang, G.; Htet, K.W.; Kwon, M.; Liu, C.; Xu, Y.; Tao, M. Freeze-thaw durability of red mud slurry-class F fly ash-based geopolymer: Effect of curing conditions. Constr. Build. Mater. 2019, 215, 381-390. [CrossRef] 
50. Sun, Z.H.; Scherer, G.W. Effect of air voids on salt scaling and internal freezing. Cem. Concr. Res. 2010, 40, 260-270. [CrossRef]

51. Zhang, D.; Weinbaum, S.; Cowin, S.C. Estimates of the peak pressures in bone pore water. J. Biomech. Eng. 1998, 120, 697-703. [CrossRef]

(C) 2020 by the authors. Licensee MDPI, Basel, Switzerland. This article is an open access article distributed under the terms and conditions of the Creative Commons Attribution (CC BY) license (http:/ / creativecommons.org/licenses/by/4.0/). 